\title{
Outbreak of Methicillin Resistant Staphylococcus aureus in Neonatal Intensive Care Unit in a Tertiary Care Hospital in Kolkata
}

\author{
Dr.Susmita Bhattacharya ${ }^{1}$, Dr.Kuhu Pal $^{2}$, Dr.Jayanta Kumar Barua ${ }^{3}$, \\ Ms. Sonia Jain ${ }^{4}$, Dr.Pratip Kumar Kundu ${ }^{5}$, Dr.Swapan Kumar Niyogi ${ }^{6}$ \\ ${ }^{1}$ Department of Microbiology,NRS Medical College, Kolkata, India) \\ ${ }_{2}^{2}$ (Department of Microbiology, College of Medicine and JNM Hospital, WBUHS, Kalyani, India) \\ ${ }^{3}$ (Department of Dermatology,Malda Medical College, Malda, India) \\ ${ }^{4}$ (Department of Microbiology, Medical College, Kolkata, India) \\ ${ }_{5}^{5}$ (Department of Microbiology, School of Tropical Medicine, Kolkata, India) \\ ${ }^{6}$ (Department of Microbiology, National Institute of Cholera \& Enteric Diseases, Kolkata, India)
}

\begin{abstract}
Infection with Methicilln resistant Staphylococcus aureus (MRSA) was not very uncommon in the Neonatal Intensive Care Units(NICU) at present. In this study we report an outbreak of MRSA infection and its successful control in a tertiary care teaching hospital, Kolkata between September 2009 and June 2010. Twelve MRSA strains were isolated and identified conventionally following Clinical and Laboratory Standards Institute (CLSI) guidelines, from various clinical specimens, sent from the NICU. Subsequently, an infection control team was formed and infection control measures including isolation of infected babies, maintenance of hand hygiene, screening for colonization with MRSA, treatment of infected as well as carrier were implemented in NICU. Demographic data were collected from clinical records. Four (4) care givers were found to be colonized with MRSA strains. Antibiogram pattern of 6 infected babies matched with the MRSA strains isolated from the colonized attendant and nursing staff. Prematurity, low birth weight and gavage feeding were established risk factors for infection with MRSA in this study. Nine neonates were found to be colonized with MRSA though none was infected with the same strain. Following control measures, only one case of MRSA was detected in October 2009 thereafter no case of MRSA was reported till June 2010.MRSA outbreak acted as an alarm to the infection control committee of this tertiary care centre of eastern India for continuous monitoring and screening for MRSA in NICU.
\end{abstract}

Keywords :MRSA, NICU, Outbreak

\section{Introduction}

Methicillin-resistant Staphylococcus aureus (MRSA) is an important cause of hospital acquired infection since the early $1980 \mathrm{~s}{ }^{[1]}$. Stay in the hospital for prolonged periods, admission in intensive care units, application of central lines, use of broad spectrum antibiotics, enteral feeding, extremes of age etc are considered as the risk factors for colonization and infection by MRSA ${ }^{[2]}$. In the neonatal intensive care units (NICU), the preterm neonates, critically ill full term babies and infants with congenital birth defects are admitted. They need use of prolonged invasive life supportive measures and antibiotics that increase the probability for acquiring healthcare associated infections ${ }^{[3]}$. Newborns with immature immune system are particularly liable to get infected with virulent organisms ${ }^{[4]}$. So, eradicating MRSA from NICU was quite an uphill task. Studies regarding incidence of MRSA outbreak in NICU, from India is not very common. In this study, we report an outbreak of MRSA in NICU in a tertiary care hospital in Kolkata followed by its control on instituting active surveillance and strict infection control measures.

Setting

\section{Material And Methods}

The NICU of the hospital is divided into two rooms - one small another large containing 8 and 12 beds respectively. There is on an average 12 admissions per day. Nearly, $90 \%$ patients in NICU are inborn. The nurse patient ratio is $1: 8$ to $1: 6$ during the study period.

\section{Outbreak:}

Routine culture send from NICU to Microbiology laboratory during September, 2009, revealed a total of 12 neonatal infections with MRSA. Among those 12 samples, 8 were pus, obtained from cases of umbilical sepsis in the neonates, 2 were endotracheal tube suction sample and 1 was blood culture sample. The $12^{\text {th }}$ sample 
was secretions from eye infection. After detection of these cases of MRSA infection, blood was collected from these infants for culture to detect septicemia if any.

\section{Infection control measures}

An infection control intervention was started from $2^{\text {nd }}$ week of October after reporting of cluster of 12 MRSA cases from NICU in the month of September, to the Hospital Infection control committee.

\section{Screening for MRSA colonization}

Screening for MRSA carriage was done on all the departmental health workers ( 5 physicians, 8 nursing staff, and 4 attendants) and mothers (4) of the affected babies available at that time and all the neonates admitted at that time in the NICU.

Samples were collected from anterior nares and both hands from adult persons with a swab stick moistened with normal saline. Along with these, swabs from perineum and umbilical swabs were also collected from the neonates to detect colonization if present.

Environmental cultures were performed from different locations of NICU like baby cot, monitor, ventilator, incubator, water tap, walls of the nursery.

\section{Identification of MRSA}

The samples were inoculated on Blood agar, MacConkey's agar and Mannitol salt agar. The yellow colored colonies on Mannitol salt agar were further tested by catalase and coagulase tests and confirmed as Staphylococcus aureus. Antibiotic sensitivity was done on Muller Hinton media at $35^{\circ} \mathrm{C}$ for 24 hours using Cefoxitin $(30 \mu \mathrm{g})$ disc to study their MRSA status ${ }^{[5]}$. The other antibiotics used were Penicillin (10 units), Vancomycin $(30 \mu \mathrm{g})$, Oxacillin $(1 \mu \mathrm{g})$, Netilmycin $(10 \mu \mathrm{g})$, Linezolid $(30 \mu \mathrm{g})$, Piperacillin-Tazobactam $(100 / 10)$, Ceftazidime $(30 \mu \mathrm{g})$, Gentamicin $(10 \mu \mathrm{g})$, Clarithromycin $(15 \mu \mathrm{g})$, Erythromycin $(15 \mu \mathrm{g})$, Clindamycin $(2 \mu \mathrm{g})$, Cefotaxime $(30 \mu \mathrm{g})$, Fusidic acid $(10 \mu \mathrm{g})$, Mupirocin $(5 \mu \mathrm{g})$, Co-trimoxazole $(25 \mu \mathrm{g})$. Quality control was performed using the S. aureusATCC 29213 strain and ATCC 43300 as control for methicillin sensitive and methicillin resistance strains respectively following CLSI guidelines ${ }^{[6]}$.

The strains marked as MRSA by Cefoxitin disc diffusion test were further confirmed by slidex staph latex agglutination tests (BioMerieux) to detect methicillin resistance based on the production of low affinity PBP2a encoded by mecA gene. The MRSA strains were kept for by PFGE and PCR for further strain typing and confirmation.

\section{Control measures}

NICU infants who were infected and colonized with MRSA were kept in isolation.

Outbreak control team was constituted. Appropriate hand hygienic measures, use of gloves, masks and isolation gown were strictly reinforced among all the health care workers in NICU. After proper hand washing with soap and water, Chlorhexidine $4 \%$ hand wash was used. Use of Alcohol based hand rub with $1 \%$ Chlorhexidine was also reinforced in between attending the patients which was not done previously before the outbreak.

The neonates with umbilical sepsis and colonization were given chlorhexidine bath (1:10 dilution) and were appropriately treated with antibiotics according to the antibiogram report.

The attendant who was a nasal carrier was treated with nasal mupirocin application three times daily for 5 days.

Barrier precautions with the use of gowns, masks, gloves were instituted for all direct patient contacts.

The medical devices and baby cots, incubators, etc. were disinfected with $2 \%$ hypochlorite solution after taking swabs.

The floor was swabbed with lysol thrice daily instead of twice a day as was done earlier.

\section{Study design}

All newborns infected with MRSA were considered as Case. The neonates who stayed in the NICU, during the period before intervention strategy were implemented and were culture negative for MRSA, were selected randomly as Control.

Demographic and clinical data were collected from medical records.

Odds ratio for risk factors were determined. Chi-Square test and Fisher exact test were applied to calculate P value. $\mathrm{P}$ value $<0.05$ was considered significant.

\section{Result}

Of the 12 neonates, 5 developed septicemia with the same MRSA strain as compared by antibiogram report. One of them died - may be because of extreme prematurity and very low birth weight. There was death in another neonate with MRSA infection due to respiratory distress syndrome in a case of prematurity. The neonates with MRSA isolate no. 8 and 9 were twins, placed side by side in the same cot. They developed 
umbilical sepsis with the same strain, one twin followed by the other one, the next day. Probably the strain was acquired from the attendant who was a nasal carrier of MRSA. Interestingly, the blood culture report showed MRSA isolate with the same sensitivity pattern in both these neonates (Table 1).

During active surveillance MRSA was isolated from 1 physician, 1 nursing staff and 2 attendants from their hands. Of the 2 attendants, one was both nasal and hand carrier. The sensitivity pattern of 3 infected neonates matched with that of the attendant who was both hand and nasal carrier. The pattern of sensitivity of 2 neonates matched with that of 1 nursing staff and 1 neonate matched with the hand swab of the no. 1 attendant (Table 2). The source of infection of the rest neonates (including the baby with eye infection) could not be determined. None of the mothers were carriers for MRSA. Colonization with MRSA was detected in 9 neonates from umbilicus. Their sensitivity pattern was similar to that of the nursing staff and the attendants. None of the 9 colonized neonates developed MRSA infection during their stay in NICU when subsequently followed up. Staphylococcus aureus isolated from different location of NICU (baby cot, monitor, incubator, walls of the nursery) was found to be sensitive to cefoxitin i.e. MSSA.

\section{MRSA incidence preceding outbreak}

2 months preceding the outbreak, the incidence of MRSA was $2.6 \%$ (5 cases of MRSA out of total 77 cultures positive cases (Table 3 ).

\section{MRSA incidence at the time of outbreak}

The MRSA incidence at the time of outbreak was 19\% (12 MRSA cases out of total 63 culture positive babies in the duration of 30days). 9 neonates and 4 health care personnel were found to be colonized with MRSA. The infected and colonized individuals were followed up with negative culture reports after adequate treatment.

\section{MRSA incidence after the outbreak}

After implementing the intervention strategy to control the MRSA infection, active surveillance was done for detection of infection and colonization for two months post outbreak. The MRSA incidence was found to be $1.6 \%$ (1 MRSA infection out of total 63 cases of infective etiology in next two months) of the total cases caused by other organisms. There were 2 colonized neonates during this period. The last case of MRSA colonization was detected at the end of December. Focused surveillance was continued till June, 2010 and no case of MRSA infection was identified during this period.

When potential risk factors for developing MRSA were considered, low birth weight, multiple pregnancies and Ryle's tube feeding appeared as significant risk factors for developing MRSA infection (Table 4).

\section{Discussion}

The MRSA strain was present in NICU as was evident from the infections before the outbreak. If proper intervention was done at that time, this outbreak may not have occurred. One of the sources may be the Health care personnel whose antibiogram pattern was found to be similar to that of the infected neonates. Similar pattern of outbreak in NICU from the colonized care givers were reported by Albrich W C et al ${ }^{[7]}$ and Saimon et $\mathrm{al}^{[8]}$. Immediate intervention was undertaken in the form of isolation, hygienic measures regarding hand washing, active surveillance, proper and strict treatment of the infected, colonized and carriers. This may have led to the control of the outbreak and reduction in the rates of MRSA colonization, infection and blood stream infection. This study confirmed prematurity and low birth weight of the neonates as significant risk factors for colonization and infection with MRSA as found by other workers ${ }^{[1,9]}$. Most of the patients had intra venous lines, and Ryle's tube feeding, which were all potential sources of infection as reported in other studies also ${ }^{[1,}$ ${ }^{10,11]}$. This further led to the exposure of the neonates to the healthcare personnel for prolonged periods; thereby increasing the chance of contracting infection. The neonates, who required prolonged stay in the NICU because of severity of their disease, prematurity etc., had more chance of contracting infection and chance of colonization. The patient and health care personnel ratio was also low in this set up, so that sometimes in case of emergency, there was a tendency for avoiding hand washing in between patients. This might be a way of introducing outbreak strain to the sick neonates. Sometimes, there is also overcrowding leading to the placement of two neonates, in the same bed like the twins in this study causing cross infection. The time period between taking a swab and receipt of the result can also be a factor in helping the spread of infection from the unknown MRSA positive infected / colonized neonate, thus acting as a source for outbreak in NICU.

Regarding the sensitivity pattern, Linezolid was $100 \%$ sensitive followed by Vancomycin which was almost $92 \%$ sensitive. One case was found to be VISA as confirmed by the E- test. The Mupirocin resistance is $25 \%$ in this study as reported elsewhere. ${ }^{[12]}$ Clindamycin is $58 \%$ sensitive in this study. So, Clindamycin is proposed as effective drug as supported in other studies. ${ }^{[13]}$ 
Two patients died. One of them had respiratory distress, another was associated with very low birth weight and prematurity so, MRSA could not be implicated as the sole cause of death.

As MRSA outbreak in NICU is very dangerous, proper and intensive infection control measures are required for proper control of infections in NICU.Along withthis, detection of recently colonized babies should be continued for prevention of this outbreak.

\section{Tables}

Table 1: Sensitivity pattern of MRSA isolated from the neonates

\begin{tabular}{|c|c|c|c|}
\hline $\begin{array}{l}\text { Isolate no. / } \\
\text { Status }\end{array}$ & Specimen & Resistance & Sensitive \\
\hline MRSA 1 & $\begin{array}{l}\text { Blood } \\
\text { culture }\end{array}$ & $\mathrm{CE}, \mathrm{CF}, \mathrm{CN}, \mathrm{CO}, \mathrm{E}, \mathrm{G}, \mathrm{OF}, \mathrm{OX}, \mathrm{P}, \mathrm{PIT}$ & CD, FC,LZ,MU,NET, VA, \\
\hline MRSA 2 & $\begin{array}{l}\text { Umbilical } \\
\text { swab }\end{array}$ & $\begin{array}{l}\text { CE, CF, CN, CO, E, FC, G, MU, NET, } \\
\text { OF, OX, P, PIT,VA ** }\end{array}$ & $\mathrm{CD}, \mathrm{LZ}$ \\
\hline MRSA 3 & $\begin{array}{l}\text { Respiratory } \\
\text { secretions }\end{array}$ & CD, CE, CF, CN, CO, E, G, MU, NET, OF, OX, P, PIT & FC,LZ,VA \\
\hline MRSA 4 & $\begin{array}{l}\text { Umbilical } \\
\text { swab }\end{array}$ & $\mathrm{CD}, \mathrm{CE}, \mathrm{CF}, \mathrm{CN}, \mathrm{CO}, \mathrm{E}, \mathrm{G}, \mathrm{OF}, \mathrm{OX}, \mathrm{P}, \mathrm{PIT}$ & FC,LZ,MU,NET, VA, \\
\hline MRSA 5 & Eye swab & $\begin{array}{l}\text { CD, CE, CF, CN, CO, E, FC, G, MU, NET, OF, OX, P, } \\
\text { PIT }\end{array}$ & LZ. OF, VA \\
\hline MRSA 6 & $\begin{array}{l}\text { Respiratory } \\
\text { secretions }\end{array}$ & $\mathrm{CE}, \mathrm{CF}, \mathrm{CN}, \mathrm{CO}, \mathrm{E}, \mathrm{FC}, \mathrm{G}, \mathrm{NET}, \mathrm{OF}, \mathrm{OX}, \mathrm{P}, \mathrm{PIT}$ & $\mathrm{CD}, \mathrm{LZ}, \mathrm{MU}, \mathrm{VA}$ \\
\hline MRSA 7 & $\begin{array}{l}\text { Umbilical } \\
\text { swab }\end{array}$ & CE, CF, CN, CO, E, FC, G, NET, OF, OX, P, PIT & $\mathrm{CD}, \mathrm{LZ}, \mathrm{MU}, \mathrm{VA}$ \\
\hline MRSA 8 & $\begin{array}{l}\text { Umbilical } \\
\text { swab }\end{array}$ & $\mathrm{CD}, \mathrm{CE}, \mathrm{CF}, \mathrm{CN}, \mathrm{CO}, \mathrm{E}, \mathrm{G}, \mathrm{NET}, \mathrm{OF}, \mathrm{OX}, \mathrm{P}, \mathrm{PIT}$ & FC, LZ, MU, VA \\
\hline MRSA 9 & $\begin{array}{l}\text { Umbilical } \\
\text { swab }\end{array}$ & $\mathrm{CD}, \mathrm{CE}, \mathrm{CF}, \mathrm{CN}, \mathrm{CO}, \mathrm{E}, \mathrm{G}, \mathrm{NET}, \mathrm{OF}, \mathrm{OX}, \mathrm{P}, \mathrm{PIT}$ & FC, LZ, MU, VA \\
\hline MRSA 10 & $\begin{array}{l}\text { Umbilical } \\
\text { swab }\end{array}$ & $\mathrm{CE}, \mathrm{CF}, \mathrm{CN}, \mathrm{CO}, \mathrm{E}, \mathrm{G}, \mathrm{NET}, \mathrm{OF}, \mathrm{OX}, \mathrm{P}, \mathrm{PIT}$ & $\mathrm{CD}, \mathrm{FC}, \mathrm{LZ}, \mathrm{MU}, \mathrm{OF}, \mathrm{VA}$ \\
\hline MRSA 11 & $\begin{array}{l}\text { Umbilical } \\
\text { swab }\end{array}$ & $\mathrm{CD}, \mathrm{CE}, \mathrm{CF}, \mathrm{CN}, \mathrm{CO}, \mathrm{E}, \mathrm{G}, \mathrm{NET}, \mathrm{OF}, \mathrm{OX}, \mathrm{P}, \mathrm{PIT}$ & FC, LZ, MU, VA \\
\hline MRSA 12 & $\begin{array}{l}\text { Umbilical } \\
\text { swab }\end{array}$ & CE, CF, CN, CO, E, FC, G, NET, OF, OX, P, PIT & $\mathrm{CD}, \mathrm{LZ}, \mathrm{MU}, \mathrm{VA}$ \\
\hline
\end{tabular}

** The MRSA strain 2 - resistant to Vancomycin has been confirmed by E test (bioMerieux) as VISA with MIC $(4 \mathrm{mg} / \mathrm{L})$.

$\mathrm{CD}=$ Clindamycin; $\mathrm{CE}=\quad$ Cefotaxime; $\quad \mathrm{CF}=\quad$ Ciprofloxacin; $\mathrm{CN}=\quad$ Cefoxitin; $\mathrm{CO}=$ Cotrimoxazole; $\mathrm{E}=$ Erythromycin; $\mathrm{FC}=$ Fucidin ; $\mathrm{G}=$ Gentamicin; $\mathrm{LZ}=$ Linezolid; MU= Mupirocin; NET= Netilmycin; $\mathrm{OF}=$ Ofloxacin; $\mathrm{OX}=$ Oxacillin; $\mathrm{P}=$ Penicillin; $\mathrm{PIT}=$ Piperacillin-Tazobactam; VA = Vancomycin

Table 2: Sensitivity pattern of MRSA isolated from health care staff

\begin{tabular}{|l|l|l|l|}
\hline \multicolumn{1}{|c|}{ Isolate no. } & \multicolumn{1}{|c|}{ Specimen } & \multicolumn{1}{|c|}{ Resistance } & Sensitive \\
\hline $\begin{array}{l}\text { Physician 1 } \\
\text { (House staff) }\end{array}$ & Hand swab & CE, CF, CN, CO, E, G, NET, OF, OX, P, PIT & CD, FC,LZ,MU, NET, VA \\
\hline Nursing staff & Hand swab & CE, CF, CN, CO, E, FC, G, NET, OF, OX, P, PIT & CD, LZ, MU, VA \\
\hline Attendant no.1 & Hand swab & CE, CF, CN, CO, E, G, NET, OF, OX, P, PIT & CD, FC, LZ, MU, OF, VA \\
\hline Attendant no.2 & Hand swab & $\begin{array}{l}\text { CD, CE, CF, CN, CO, E, G, MU,NET, OF, OX, , P, } \\
\text { PIT }\end{array}$ & FC,LZ,VA \\
\hline Attendant no.2 & Nasal swab & CD, CE, CF, CN, CO, E, G, NET, OF, OX, P, PIT & FC,LZ,MUVA \\
\hline
\end{tabular}

Table 3: Laboratory culture positive infections during the study period

\begin{tabular}{|c|c|c|c|c|c|}
\hline & \multicolumn{2}{|c|}{ Before outbreak } & \multirow{2}{*}{$\begin{array}{c}\text { During outbreak } \\
\text { September }\end{array}$} & \multicolumn{2}{|c|}{ After outbreak } \\
\hline Month & July & August & & October & November \\
\hline MRSA & 03 & 02 & 12 & 01 & 00 \\
\hline Staphylococcus spp. other than MRSA & 20 & 16 & 26 & 13 & 14 \\
\hline Other Gram positive pathogens & 03 & 04 & 04 & 02 & 05 \\
\hline Gram negative pathogens & 11 & 14 & 19 & 08 & 16 \\
\hline Fungi & 02 & 00 & 02 & 01 & 03 \\
\hline Positive culture & 41 & 36 & 63 & 25 & 38 \\
\hline
\end{tabular}


Table 4: Potential risk factors for MRSA infection

\begin{tabular}{|l|l|l|l|}
\hline & $\begin{array}{l}\text { MRSA+ } \\
\text { No=12 }\end{array}$ & $\begin{array}{l}\text { MRSA- } \\
\text { No=375 }\end{array}$ & Statistics \\
\hline Respiratory distress Present $\left(\mathrm{n}_{1}=39\right)$ & 2 & 37 & Odds ratio $1.827, \chi^{2}=0.080$ with $1 \mathrm{df}$, \\
Respiratory distress Absent $\left(\mathrm{n}_{2}=348\right)$ & 10 & 338 & $\mathrm{p}=0.77$ \\
\hline Birth wt $<1.5 \mathrm{~kg}\left(\mathrm{n}_{1}=25\right)$ & 10 & 15 & Odds ratio $=120, \chi^{2}=108.339$ with $1 \mathrm{df}$ \\
Birth wt $\geq 1.5 \mathrm{~kg}\left(\mathrm{n}_{2}=362\right)$ & 2 & 360 & $\mathrm{p}=0.000$ \\
\hline Multiple pregnancy Present $\left(\mathrm{n}_{1}=7\right)$ & 3 & 4 & Odds ratio=30.917, $\chi^{2}=25.237$ with $1 \mathrm{df}$ \\
Multiple pregnancy Absent $\left(\mathrm{n}_{2}=380\right)$ & 9 & 371 & $\mathrm{p}=0.000$ \\
\hline Apgar score $<3\left(\mathrm{n}_{1}=53\right)$ & 2 & 51 & Odds ratio=1.271, $\chi^{2}=0.015$ with $1 \mathrm{df}$ \\
Apgar score $\geq 3\left(\mathrm{n}_{2}=334\right)$ & 10 & 324 & $\mathrm{p}=0.903$ \\
\hline Congenital anomaly present $\left(\mathrm{n}_{1}=4\right)$ & 1 & 3 & Odds ratio $=11.273, \chi^{2}=1.188$ with $1 \mathrm{df}$ \\
Congenital anomaly absent $\left(\mathrm{n}_{2}=383\right)$ & 11 & 372 & $\mathrm{p}=0.276$ \\
\hline Male $\left(\mathrm{n}_{1}=221\right)$ & 8 & 213 & Odds ratio $=1.521, \chi^{2}=0.147$ with $1 \mathrm{df}$ \\
Female $\left(\mathrm{n}_{2}=166\right)$ & 4 & 162 & $\mathrm{p}=0.701$ \\
\hline Ryle's tube feeding Present $\left(\mathrm{n}_{1}=27\right)$ & 8 & 19 & Odds ratio=37.474, $\chi^{2}=58.826$ with $1 \mathrm{df}$ \\
Ryle's tube feeding Absent $\left(\mathrm{n}_{2}=360\right)$ & 4 & 356 & $\mathrm{p}=0.000$ \\
\hline Undergone C.S $\left(\mathrm{n}_{1}=131\right)$ & 2 & 129 & Odds ratio $=0.381, \chi^{2}=0.937$ with $1 \mathrm{df}$ \\
Vaginal delivery $\left(\mathrm{n}_{2}=256\right)$ & 10 & 246 & $\mathrm{p}=0.333$ \\
\hline
\end{tabular}

\section{Conclusion}

The MRSA strains were present in the NICU and went unrecognized till the outbreak occurred. So, it is important to take intensive control measures even with a few cases. The increased susceptibility of the premature and very low birth weight babies to infection and presence of carriers of MRSA in NICU was responsible for the outbreak. The major intervention in the form of maintenance of hand hygiene with its strict compliance among the health care personnel, detection of carriers, and active surveillance of colonized neonates frequently combined with Mupirocin treatment has been successful in controlling such outbreaks. The health care givers should be screened at intervals for early detection and treatment of carriers. A continued education of health care personnel is also important in reducing the incidence of MRSA, so that outbreaks do not occur.

\section{Limitations}

The limitation of the study is that the isolated strains could not be genetically typed on the basis of repetitive sequence PCR or pulsed field gel electrophoresis as was done by other authors ${ }^{19}$ for epidemiological study because of the cost involved. But the strains have been preserved for future study.

\section{Acknowledgements}

We are indebted to "The West Bengal University of Health Sciences" in allowing us to publish this paper as a part of the thesis work entitled "Characterization of methicillin resistant Staphylococcus aureus isolated from surgical wound infection in a tertiary care hospital in Kolkata by phenotypic and genotypic methods" (PhD in Medicine) of Dr. Susmita Bhattacharya, Professor, Microbiology, NRS Medical College, Kolkata.

\section{References}

[1]. Khoury J, Jones M, Grim A, Dunne WM Jr, Fraser V . Eradication of methicillin-resistant Staphylococcus aureus from a neonatal intensive care unit by active surveillance and aggressive infection control measures. Infect ControlHospEpidemiol2005; 26: 616-621.

[2]. Graffunder E.M, Venezia A. R. Risk factors associated with nosocomial Methicillin resistant Staphylococcus aureus(MRSA) infection including previous use of antimicrobials. Journal of antimicrobial chemotherapy 2002; 49: 999-1005

[3]. Ramsing BGU, Arpi M, Andersen EA, Knabe N, Mogensen D, et al. First Outbreak with MRSA in a Danish Neonatal Intensive Care Unit: Risk Factors and Control Procedures. PLoS ONE 2013; 8(6): e66904. doi:10.1371/journal.pone.0066904

[4]. Guha D.K, Saili A. Guha R, Aggarwal A. Common Infections in the Newborn. In: Neonatology - Principles and Practice. Guha D.K; 3rd ed Jaypee Brothers Medical Publishers (P) Ltd. New Delhi, India; 2005: 654 - 672.

[5]. Amita Jain, AsthaAgarwal and Raj Kumar Verma. Cefoxitin disc diffusion test for detection of meticillin-resistant staphylococci, Journal of Medical Microbiology 2008; 57: 957-961

[6]. Clinical and Laboratory Standards Institute. Performance standards for antimicrobial susceptibility testing, 17th informational supplement (M100-517). Wayne, Pa: Clinical and Laboratory Standards Institute; 2007.

[7]. Albrich WC, Harbarth S. Health-care workers: source, vector, or victim of MRSA? Lancet Infect Dis 2008;8: 289-301.

[8]. Saiman L, Cronquist A, Wu F, Zhou J, Rubenstein D, et al. An outbreakof methicillin-resistant Staphylococcus aureus in a neonatal intensive care unit. InfectControl HospEpidemiol2003;24: 317-321.

[9]. Vergnano S, Menson E, Smith Z, Kennea N, Embleton N, et al. (2011) Characteristics of invasive Staphylococcus aureus in United Kingdom neonatalunits. Pediatr Infect Dis J 2011;30: 850-854.

[10]. GiliRegev-Yochay, Ethan Rubinstein, Asher Barzilai, Yehuda Carmeli, Jacob Kuint, Jerome Etienne, Mira Blech, Gill Smollen, Ayala Maayan-Metzger, Azita Leavitt, GaliaRahav, and Nathan Keller . Methicillin-resistant Staphylococcus aureus in Neonatal Intensive Care Unit, Emerging Infectious Diseases 2005; 11: 453 - 456

[11]. Silvia Iacobelli, Benoit Colomb, Francesco Bonsante1, KarineAstruc, Cyril Ferdynus, Marie-France Bouthet, Catherine Neuwirth, Ludwig Serge AhoGlélé, Pascal Chavanet and Jean-Bernard Gouyon. Successful control of a Methicillin-resistant Staphylococcus aureus outbreak in a neonatal intensive care unit: a retrospective, before-after study.BMCInfectious Diseases 2013; 13: 440 - 449

[12]. M-N Kim, H Kim, D An, M Ji, M Lee, A-R Kimand SJ Lee.Mupirocin resistance among MRSA surveillance isolates from neonatal intensive care unit under 10 year-search and destroy policy. BMC Proceedings 2011;5(Suppl 6): 171

[13]. Frank AL, Marcinak JF, Mangat PD, Tjhio JT, Kelkar S, Schreckenberger PC, Quinn JP. Clindamycin treatment of Methicillin-resistant Staphylococcus aureus infections in children, Pediatr Infect Dis J 2002; 21(6): 530 - 4. 